\title{
Public Participation GIS (PPGIS) for Regional Mapping and Environmental Awareness
}

\author{
Simon Foteck Fonji' ${ }^{1}$ Michael Larrivee', Gregory N. Taff ${ }^{2}$ \\ ${ }^{1}$ Department of Earth Sciences, University of Memphis, Memphis, USA \\ ${ }^{2}$ Norwegian Forest and Landscape Institute, Norway \\ Email: sffonji@memphis.edu, crunchierbob@yahoo.com
}

Received 17 December 2013; revised 21 January 2014; accepted 15 February 2014

Copyright (C) 2014 by authors and Scientific Research Publishing Inc.

This work is licensed under the Creative Commons Attribution International License (CC BY). http://creativecommons.org/licenses/by/4.0/

(c) (i) Open Access

\begin{abstract}
Giant Hogweed is a poisonous invasive weed in Latvia that poses significant threat to biodiversity and human health. Local residents are afraid and have very special concerns about the safety of their children because the plant causes phytophotodermatitis (severe burns), painful blistering, permanent scarring and blindness when the sap of the plant comes in contact with the human body and is exposed to sunlight. This study utilizes public participation GIS (PPGIS) involving Latvian high school students as data collectors to monitor the geographic distribution of Giant Hogweed in Northeast Latvia. This paper also explores challenges with implementing such a public program, how to maximize participation, and how participation impacts environmental awareness of participants. In this study we also assessed the accuracy of PPGIS-collected data and how the utilization of such data impacts mapping and monitoring of Giant Hogweed in the study area. Results indicate that this PPGIS program is effective in facilitating data collection for monitoring Giant Hogweed in Latvia. Tested methods of increasing participation have proven largely unsuccessful to date. Statistical analyses of survey responses indicate participation had a marked effect on sensitivity towards environmental issues. Accuracy assessments indicate that quality of point data collected by participants is sufficient for mapping and for use as ground verification.
\end{abstract}

\section{Keywords}

GIS, PPGIS Mapping, Google Maps, Invasive Species, Environmental Awareness, Latvia

\section{Introduction}

This paper addresses mapping done by local residents (mainly Latvian high school students) to locate Giant Hogweed populations and to create environmental awareness of the dangers posed by this poisonous invasive plant. Mankind has addressed the problems associated with invasive plant species throughout history. With re- 
cent explosions in globalization and vastly increased connectivity, there has been an equally explosive growth in the number and scope of invasive species across the globe, especially in the last fifty years [1]. Invasions by non-native plants can have disastrous effects on human health and activity, and can in some circumstances have irreversible effects on the environment. Next to habitat loss, invasive species is considered to be the greatest threat to biodiversity [2]. Some species, however, not only damage the landscape and negatively impact native ecosystems, they also pose a significant risk to human health. Giant Hogweed (Heracleum sosnowskyi) is such a species, and it is the most common of the three Giant Hogweed species found throughout Latvia.

It was promoted as a crop for cattle feed in northwest Russia, where it was first introduced in 1947. From the 1940s onwards, it was introduced as a fodder plant to Latvia, Estonia, Lithuania, Belarus, Ukraine and the former German Democratic Republic (Nielsen et al., 2005) [1]. H. sosnowskyi was sown as a fodder plant for the first time in Latvia in 1948 and was grown on experimental agricultural farms [3]. Heracleum sosnowskyi is a biennial or perennial herb in the carrot family (Apiaceae) which can grow up to 12 feet or more and its large compound leaves can grow up to 5 feet wide. A single plant can produce up to 100,000 seeds with a high viability rate. Because of its size and rapid growth, it out-competes native plant species by providing shade for native plants that are much in need of sunlight [1]. The mode of dispersal of the plant is by both natural and human activities. The seeds are dispersed by running water, floods, wind and by human. In Latvia $H$. sosnowskyi species is mostly found in artificial habitats (roadsides), disturbed areas, agricultural fields, abandoned farm yards and gardens and seminatural habitats (bushes, grasslands, parks, pastures, abandoned orchards) [4].

The effects of $H$. sosnowskyi on humans and the environment are well documented. The Hogweed plant is poisonous to humans and can be fatal if ingested, but the primary need for control of the species arises from the toxic properties of Hogweed sap, and its negative health effects on humans and domestic animals.

This project builds upon prior research conducted in which PPGIS programs have been utilized to address issues of environmental quality [5] natural resource conservation [6], and the preservation of biodiversity [7]. We explore the use of PPGIS data in mapping Giant Hogweed in Latvia and to create environmental awareness of the dangers posed by this poisonous weed. At the time of this writing, no instances have been identified wherein a PPGIS program was employed specifically to inventory an invasive plant species. Demonstrating the effectiveness of this type of data collection in addressing environmental issues is the goal of this research (Figure 1).

Some specific research questions of interest are:

1) How can a PPGIS system be effectively developed for Latvian high school students and other interested parties to help monitor and eventually control Giant Hogweed, and also receive important relevant education in the process?"

2) How can participation in this program be maximized?

3) What challenges are involved in utilizing the public for the collection of data in the effort to monitor Giant Hogweed in Latvia?

4) What are current levels of awareness of high school students regarding Giant Hogweed and other environmental issues, and how will participation in this program affect their awareness of these topics?

\section{Methods}

\subsection{Study Area}

Our study was conducted in northeast Latvia which lies on the Baltic coast, in the western part of Eastern Europe. Latvia is one of the three Baltic States, situated on the east side of the Baltic Sea, the others being Estonia (to the north) and Lithuania (to the south). Latvia also borders Russia and Belarus to the east (Figure 2). The total land area is 64.6 thousand $\mathrm{km}^{2}$ and the terrain is mostly low plain, with majority of the territory between 40 - 200 meters above sea level [8]. The climate is wet with moderate winters for this latitude. The average amount of precipitation is 600 - $650 \mathrm{~mm}$ annually; the vegetation period usually last for 180 - 200 days [9]. The average temperature is $16.5^{\circ} \mathrm{C}$. The landscape is characterized by mature forests, secondary forests, meadows, farmland, abandoned farmlands, lakes, rivers, hills, plains, villages and dispersed rural homesteads [10]. Some of these land cover types have been invaded by Giant Hogweed where it develops large stands and dominates native species in occupied territories. It is easy to distinguish it from the surrounding vegetation especially during summer when the plant flowers. As Giant Hogweed capitalizes on the ideal growing conditions it finds in these areas, the pastoral landscape with which many Latvians strongly identify themselves is significantly altered [11]. As of 2001, an estimated 12,000 hectares of land in Latvia was occupied by Giant Hogweed [12]. Most of the study 


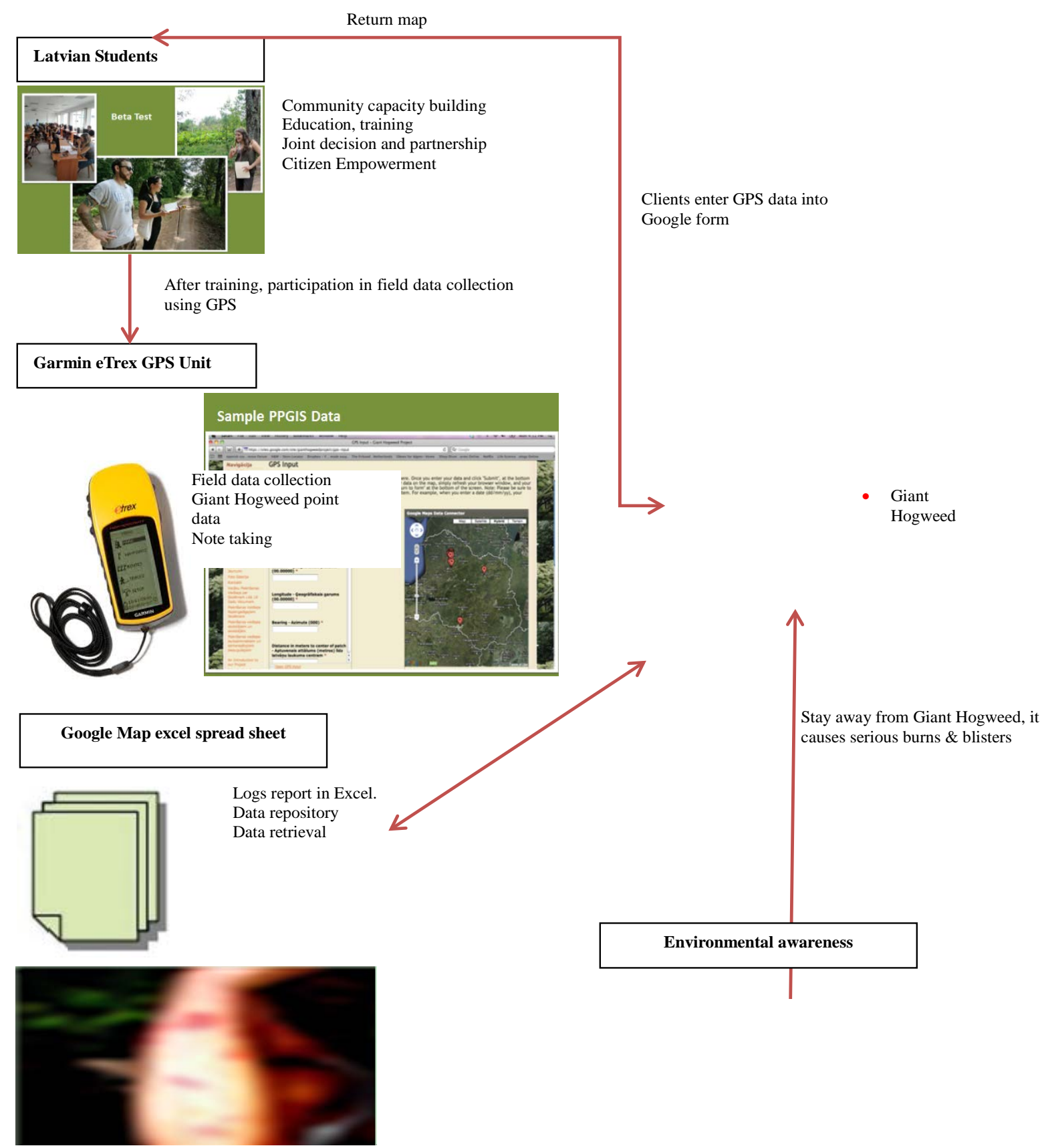

Figure 1. Project summary flow chat of PPGIS and environmental awareness.

was carried out in Madona, Cesis, and Valmiera. In some heavily infested are as within Gauja National Park (GNP), Giant Hogweed accounts for eighty-five percent of the vegetation [12]. This region was chosen as the study site because it is where the species was first introduced in the country and existing records of the study species in this region show a substantial distribution, and many Giant Hogweed patches are large when compared to other areas.

\subsection{Data Collection}

\subsubsection{Public Participation GIS}

Public participation GIS (PPGIS) promotes the participation of grass roots communities to utilize GIS in 


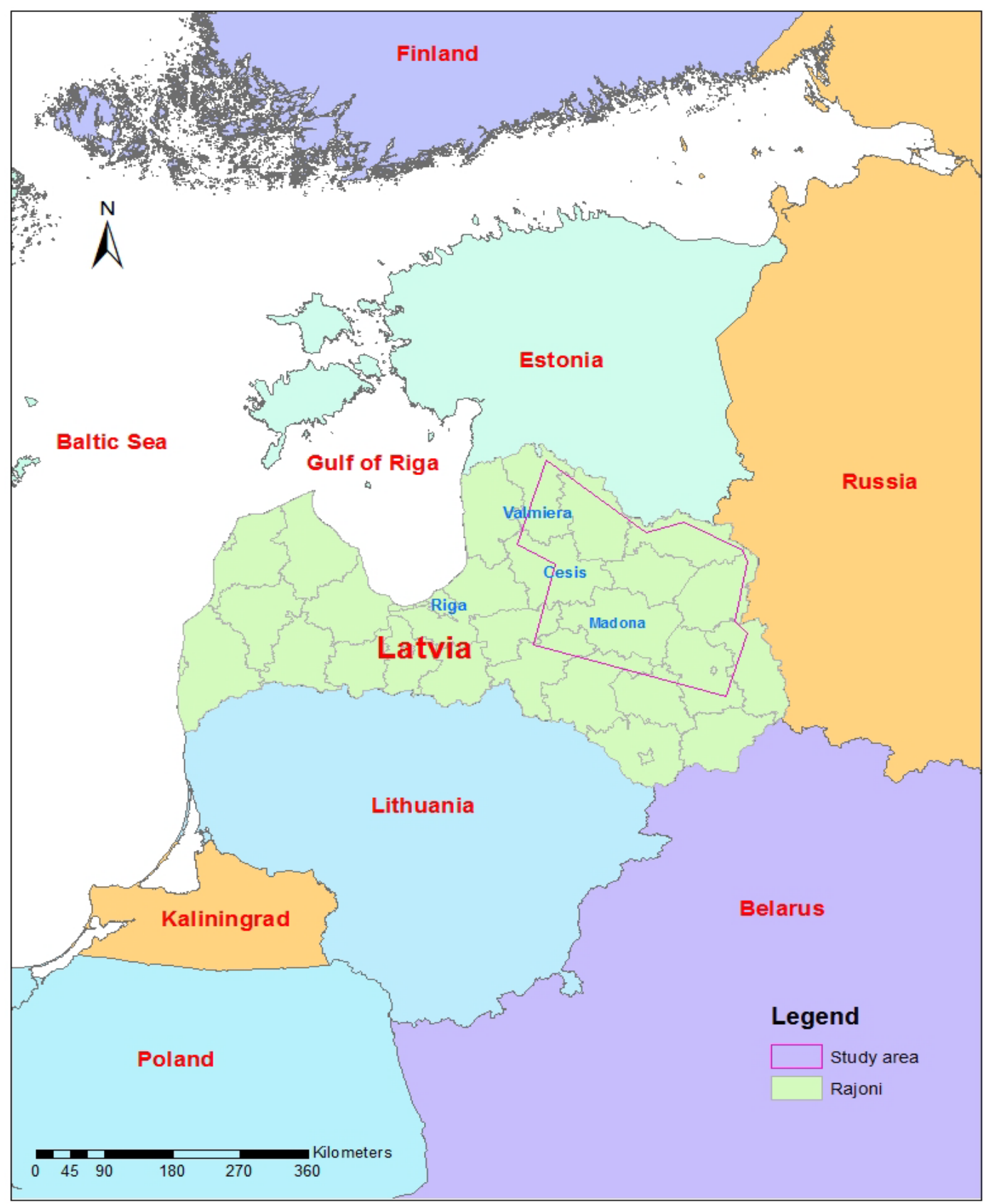

Figure 2. Study area-north-eastern latvia.

processes that affect their everyday lives. In this project we used a participatory bottom-up approach that involves community throughout the process, from identifying the issues examined to participating in data collection and discussions of action steps [13]. Given that scientific data of Giant Hogweed in this region is incomplete, coupled with the fact that the spatial distribution of invasive species is continuously changing and that it might not be possible to gather data to capture such dynamics at larger scales, PPGIS is a strategic means to compensate for the lack of data. PPGIS was chosen for this project for the following reasons: 1) it has the potential to accumulate large amounts of long-term data required to construct predictive models, which may otherwise be difficult to collect [7]. 2) It tends to bridge the gap between citizens, researchers and policy makers in combating Giant Hogweed and to ensure collaboration between universities (as partners) and local communities. 3) It also offers concerned scientists an opportunity to engage and educate the public, and it offers the public an 
avenue to become a part of the scientific process required to provide solutions to the sea of environmental problems that we face today.

According to Fleming 2001, it also offers an opportunity for stakeholders to take an active role in issues that affect them directly, and generally serves to increase local knowledge on environmental issue that affect the area. This is not to say that PPGIS is without its drawbacks and problems. It can be difficult to engage the community in issues with which they are uninformed or disinterested [6]. Even as the world becomes more technologically connected, access to and knowledge of computer technology remains inconsistent. Uneven distribution of willing volunteers can lead to gaps in spatial data [14]. Data quality is always an issue, as many PPGIS projects are still technical in nature, and require a level of scientific skill/knowledge that may not be present in the community. Local volunteers may be required to participate in a training program that ensures data is collected in a uniform and useable format [15].

This project incorporates a PPGIS program with a strong educational element. This aspect of the program provided research partners with a foundational knowledge of GIS and GPS technologies (including the operation of a handheld GPS unit).

Participation was open to high school students from selected Latvian high schools, local residents and experts with a sound knowledge of Giant Hogweed and the danger it poses to the public. Participants used a Garmin eTrex handheld GPS unit to collect data points in their area indicating the presence of Giant Hogweed, and upload that information to a spreadsheet stored on a web site.

For this to be successful, we created a web-based GIS system, that is designed to provide detailed instruction on participants' roles as data collectors, and provides a platform for uploading collected data of Giant Hogweed plants recorded in the field, after they have completed a training module. We developed a Google Map-based system for our website (http://sites.google.com/site/gianthogweedproject/), which makes user interaction and data entry simple, fast, and intuitive. Google Maps software was selected because it has several advantages over commercial mapping software such as, it is free, map locations can be display with several icons and spread sheets and maps can be shared over the internet through e-mails. One limitation of using Google Maps is that both the mapping interface and database (Google docs) are hosted by Google's servers, thus limiting our control over data storage but is nonetheless effective and an elegant/simple design. Google split the world into multiple 256-pixel square image tiles for each zoom level; as a result a user actually sees multiple separate image tiles that comprise the viewable portion of the map. Therefore just a handful of image tiles need to be refreshed when a user moves a map or zooms in. A complete description of the process Google Maps uses is given in [16]. The web mapping system consists of two main components, a mapping interface and a database. Users interact with the mapping interface to enter data for each Giant Hogweed point location, while the database stores user responses and marker coordinates.

\subsubsection{Mapping Interface}

Users of the website were asked to take an online course, pass a test given to them by their teachers, sign an online consent form and have their parents/guardians sign a parental consent form before they could be invited to participate and given a GPS unit to collect points of Giant Hogweed locations in the field to gain access to the mapping system. This allowed us to capture affiliation and contact information as well as track the input of each user to the system. As participants to the project, users are allowed to add data over multiple sessions but they cannot edit the data entered once they hit the "submit" button.

We used the freely available Google Maps Application Programming Interface (API), which allows for an instance of the Google Maps application to be embedded in a website. Google Maps API performs two important roles:

1) By simply submitting the spatial parameters to the Google Maps form web service, the corresponding coordinates are returned to the client.

2) The Google Maps API provides a means to generate customized symbols to be drawn in the map.

The website is open to the public which means any person can have access to the website i.e. read and view all the pages of the website. To enter data, we require a user who is under age 18 years, to sign a student-participant-consent form and have his/her parents/guardians sign a parental consent form before he/she can participate in the project. Students older than 18 years must sign the student-participant-consent form. Professionals involved with Giant Hogweed and other interested adults must sign a non-student-participant form. To enter data, a user needs to visit our web site and then click on the GPS input page. The GPS input form is linked to a 
Google Doc form and a Google Map. Personal information as well as the GPS point locations of Giant Hogweed are entered in the Google Doc form. Upon clicking the "submit" button the input data are transferred to the database which automatically updates (point locations only) in the Google map via a Google Maps data connector as markers after about one minute. For instant updates on the Google Map, however, the user must refresh the page. When a marker is clicked or the mouse is simply pointed towards the marker, information about the location is shown (latitude and longitude). The GPS location points shown on this map are not the exact location points because they were taken at an estimated distance and bearing from the poisonous Giant Hogweed plant for safety reasons. Therefore, we had to correct for all the estimated distances and bearings of the GPS points collected in field (and stored in the Google Docs Spreadsheet, described below) using a formula in excel and then remap all the new GPS point data in Google map. To view this map, users will need to click on the data input layer on our web site and click this link (http://maps.google.com/maps?hl=en\&mid=1284943086).

\subsubsection{Databases}

Google Document (Docs) allows you to work with three kinds of documents: word-processing documents, spreadsheets, and presentations. We used Google Docs spreadsheet database software to store data entered by each user and the coordinates of each Google marker (called a gadget) indicating the presence of Giant Hogweed. JavaScript is used for communication between the database and the mapping interface. Once a user clicks the submit button on the data entry form, the information he/she entered goes to the database. If that information was successfully stored, the database sends a response to the website that read "Thanks! Your response will now appear in the spreadsheet to notify the user of a successful submission”.

\subsection{Basic Architecture}

The whole system is based on the established technologies readily available and usable on the internet. The form is integrated in a simple HTML page, which is served by an Apache HTTP Server. Javaservlets are used at the server side to manage database access, data storage and forwarding of requests. It is further used for communicating with Java Scripts, which play the key role in using the Google Maps API (Figure 3).

1) The user enters the coordinates (lat/long) of Giant Hogweed recorded in the field using a GPS unit by filling out and submitting the form on a web page.

2) The whole report (including coordinates) is saved in the database (in excel spread sheet) for archiving and further processing.

3) Coordinates are sent to Google Maps API together with symbol information.

4) Google Maps API returns a map with system-specific symbols showing Giant Hogweed locations. Map is integrated into web page and returned to client synchronously.

\section{Discussions/Results}

\subsection{To Answer Research Question \#1}

we developed a web-based GIS program in which high school students are able to act as research partners. The beta test-discussed in greater detail later in this section proved that the website functions as a tool capable of communicating the goals and purpose of this research, the role of participants within it, providing educational materials to those participants, and as an effective means of collecting and storing point data to be used in analysis.

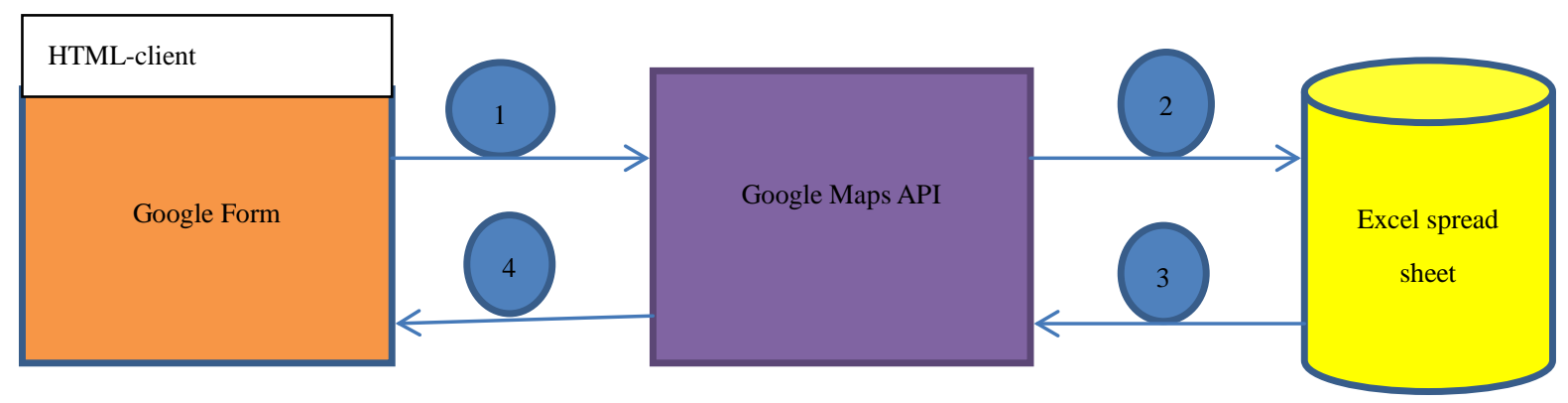

Figure 3. Conceptual system architecture. 
Statistical analysis indicates that the program has also had impact on student participant's environmental awareness and provided them with knowledge regarding the impact of Giant Hogweed.

\subsection{How Can Participation in This Program Be Maximized?}

Involvement in the program was maximized through a "grass roots", bottom up approach. Participants in the beta test for the program acted as ambassadors to their respective schools distributed throughout Latvia. These initial schools will act as spreading centers, and the attention generated by their activity will spread the program to schools in other areas. In addition, a number of media outlets were approached in an attempt to increase the visibility of this project.

\subsection{What Challenges Are Involved in Utilizing the Public for the Collection of Data in the Effort to Monitor Giant Hogweed in Latvia?}

\subsubsection{Lack of Participation/Data}

A number of obstacles restricting the flow of progress of the project have emerged in the period following beta testing. Communication with teachers at schools who student beta test participants were able to convince to volunteer to participate in the project has been very limited.

\subsubsection{Language}

The Latvian/English language barrier has represented an obstacle in the forward progress of the project. Although the website is available in Latvian, a significant amount of personal correspondence is required between University of Memphis researchers and teachers as participating schools. It is unclear to what extent language has impacted the level of communication, but very little communication has actually occurred.

\subsubsection{Distance/Cost}

Distance from base of operations and the study area has been an issue. The research team only had funds to provide 4 GPS units to 4 high schools at the end of the beta test. Shipping additional units from Memphis to Latvia to remedy this issue has proven to be cost prohibitive.

\subsubsection{Internet Access}

One volunteer student reported Internet access issues that prevented the opening of the project website on school computers. Lack of accessibility and restriction on what type of web-pages that may be viewed from schoolowned computers is likely to reduce participation.

\subsection{What Are Current Levels of Awareness of High School Students Regarding Giant Hogweed and Other Environmental Issues, and How Will Participation in This Program Affect Their Awareness of These Topics?}

A number of statistical methods were employed in an attempt to understand the background and breadth of knowledge of the beta test subjects regarding Giant Hogweed, the problem of invasive species, and of environmental problems in general. Perhaps more importantly, these processes were also designed to provide insight into whether participation in the program has had any impact on their environmental awareness. Following is the output of procedures conducted in SPSS based on the surveys taken by the high school students in the beta test and a summary of their analysis. It is important to understand that due to the small $\mathrm{n}$ (sample size), most statistical tests conducted in this research do not have significant results, and the chi-square tests for the cross-tab analyses are invalid due to expected cell sizes of less than 5 . However, while many analyses do not have sufficient sample size to show statistical significance, they do indicate trends.

\subsubsection{Key to Rank System, as Used in Surveys}

The ranking system for the surveys is based on a low positive (1), high negative (5) ranking system. See below for precise descriptions of values.

$1=$ Very Important/Very Good

$2=$ Important $/$ Good

$3=$ Neutral/Fair 
$4=$ Not very Important $/$ Poor

$5=$ Not at All/Very Poor

\subsubsection{Statistical Analyses: Cross Tabulations}

Cross tabulations were run on pairs of categorical variables from website surveys in order to test their association. Cross tabulations (Table 1, Table 2, Table 7, Table 8 and Table 12) were taken from the Introductory Survey and provide some insight into the knowledge and experience of student participants prior to their participation in the program.

\subsubsection{Statistical Analyses: Histograms and t-Tests (Mann-Whitney)}

Histograms are graphic representations of single variable analyses performed here to provide a side-by-side comparison of participant response before and after participation in the PPGIS program. Although there were different $\mathrm{n}$ values for the Introductory Survey (16) and Outgoing Survey (10), percentages of responses and changes in response percentages are discussed in each summary.

Mann-Whitney tests were performed to determine statistical significance of association between an ordinal variable and a binary categorical variable. In these analyses, the binary categorical variable reflected the before or after survey. The significance of the change in mean rank was tested for before vs. after participation in the program. Even in cases where significance was not achieved, these analyses summarized any change in mean rank of participant response to each variable. These changes in rank indicate best estimate of changes (positive or negative) in the environmental perception of participant.

Results (Table 1) indicate that most participants (13 out of 16) have known about Giant Hogweed for more than five years. Results also indicate that all (100\%) participants who learned about Giant Hogweed from school or through media outlets have been aware of Giant Hogweed for more than five years, while a slightly smaller percentage (76.9\%) of those that learned of Giant Hogweed from their parents or guardians have been aware of Giant Hogweed for more than five years. In addition, $15.4 \%$ of the participants (2 out of 16 ) have learned of Giant Hogweed only since learning of this project. This last percentage indicates that this PPGIS program has the potential to inform a small but substantial percentage of student participants of the dangers of Giant Hogweed.

Results (Table 2) indicate that participants who have been injured or know someone who has been injured by Giant Hogweed are more likely to believe that their work on this research project with have an impact on the control and eradication of Giant Hogweed-77.8\% of responses, as compared with $42.9 \%$ of responses for those who have not been injured nor know someone who has been injured by Giant Hogweed. This result implies that participants that have more experience with Giant Hogweed feel more certain that working towards the control of Giant Hogweed will bear fruit. The landscape knowledge provided by these individuals has high potential, as it could be very useful when collecting data in their home areas.

Table 1. Cross tabulation output for the survey variables "how long have you known about giant hogweed?” vs. "where did you learn about giant hogweed?”.

\begin{tabular}{|c|c|c|c|c|c|c|}
\hline & & & \multicolumn{3}{|c|}{ How did you learn about Giant Hogweed? } & \multirow[t]{2}{*}{ Total } \\
\hline & & & From parents/Guardians & Media & School & \\
\hline \multirow[t]{6}{*}{$\begin{array}{l}\text { How long have you known Giant } \\
\text { Hogweed is dangerous? }\end{array}$} & More than 5 years & Count & 10 & 2 & 1 & 13 \\
\hline & & Column\% & $76.9 \%$ & $100.0 \%$ & $100.0 \%$ & $81.3 \%$ \\
\hline & Since project & Count & 2 & 0 & 0 & 2 \\
\hline & & Column\% & $15.4 \%$ & $0.0 \%$ & $0.0 \%$ & $12.5 \%$ \\
\hline & $<1 \mathrm{Yr}$ & Count & 1 & 0 & 0 & 1 \\
\hline & & Column\% & $7.7 \%$ & $0.0 \%$ & $0.0 \%$ & $6.3 \%$ \\
\hline \multirow{2}{*}{ Total } & & Count & 13 & 2 & 1 & 16 \\
\hline & & Column\% & $100.0 \%$ & $100.0 \%$ & $100.0 \%$ & $100.0 \%$ \\
\hline
\end{tabular}


Table 2. Cross tabulation output for the survey variables "have you or someone you know been injured by Giant Hogweed?” vs. “do you think your work in this project will have an impact?”.

\begin{tabular}{|c|c|c|c|c|c|}
\hline & & & \multicolumn{2}{|c|}{ Injured? } & \multirow[t]{2}{*}{ Total } \\
\hline & & & No & Yes & \\
\hline \multirow[t]{6}{*}{ Impact? } & Yes & Count & 3 & 7 & 10 \\
\hline & & Column\% & $42.9 \%$ & $77.8 \%$ & $62.5 \%$ \\
\hline & Not sure & Count & 4 & 2 & 6 \\
\hline & \multirow{3}{*}{ Total } & Column & $57.1 \%$ & $22.2 \%$ & $37.5 \%$ \\
\hline & & Count & 7 & 9 & 16 \\
\hline & & Column\% & $100.0 \%$ & $100.0 \%$ & $100.0 \%$ \\
\hline
\end{tabular}

Results (Figure 4) indicate that prior to participation in the program, $62.5 \%$ of respondents felt their work on this project would have an impact, while $37.5 \%$ felt unsure whether or not their work would have an impact. There were no responses for "no". Following participation, $40 \%$ of respondents felt their work on the project would have an impact, while $60 \%$ felt uncertain whether or not their work would have an impact. There were no responses for "no". These results indicate a significant shift to the negative (participants felt less confident that their work would have an impact) in responses after participation in the program. This is important, as it indicates that more should be done in the academic and training portions of the PPGIS programs to reinforce the value of individual participation. This also suggests that the research team may look for more ways to keep students involved in the project and in pursuing Giant Hogweed eradication goals upon their completion of data collection.

Mean rank of participant response to this question decreased (shifted toward participants feeling less confident their work on the project would have an impact) from 12.38 prior to participation to 15.30 after participation-a difference of 2.92 (Table 3). Running a Mann-Whitney test for significance in difference of mean rank between two groups, the p-value of 0.363 indicates a lack of significance, so the null hypothesis should be accepted (Table 4).

Results (Figure 5) indicate that before participating in this program $50 \%$ of participants thought they could "Always" identify Giant Hogweed, and 37.5\% of participants thought they could "Usually" identify Giant Hogweed (87.5\% combined). 6.25\% thought they could identify Giant Hogweed "Sometimes”, and another 6.25\% thought they could identify it "Rarely". Results from the survey taken after participation in this program indicate that participants felt they were now able to "Always" identify Giant Hogweed $60 \%$ of the time and "Usually" identify Giant Hogweed $40 \%$ of the time (100\% total). There were no responses in the outgoing survey for participants being able to identify Giant Hogweed "Sometimes", "Rarely", or "Never". These results indicate that participants were more likely to feel they could positively identify Giant Hogweed after participation in the program than they were prior to participation. This knowledge will help in the data collection process, and may prevent injuries in the long-run.

Mean rank of participant response to this question increased (shifted towards participants feeling more confident about identifying Giant Hogweed) from 14.25 prior to participation to 12.30 after participation-a difference of 1.95 (Table 5). Running a Mann-Whitney test for significance in difference of mean rank between two groups, the p-value of .551 (Table 6) indicates that while the trend is towards feeling more able to identify Giant Hogweed after participation in the program, there is a lack of statistical significance.

Results (Figure 6) indicate that $43.75 \%$ of participants considered environmental issues to be "Very Important", and $43.75 \%$ of participants considered environmental issues to be "Important" prior to participation in the program (87.5\% total). $6.25 \%$ of participants had either a "Neutral" opinion on environmental issues or felt that environmental issues were "Not Very Important". There were no responses for "Not At All". After participation, $70 \%$ of participants indicated that they felt environmental issues were "Very Important", while $30 \%$ felt that environmental issues were "Important" (100\% total). There were no responses for "Neutral", "Not Very Important" or "Not At All". As hypothesized, these results indicate that environmental issues became of greater importance to respondents after participating in the program. 

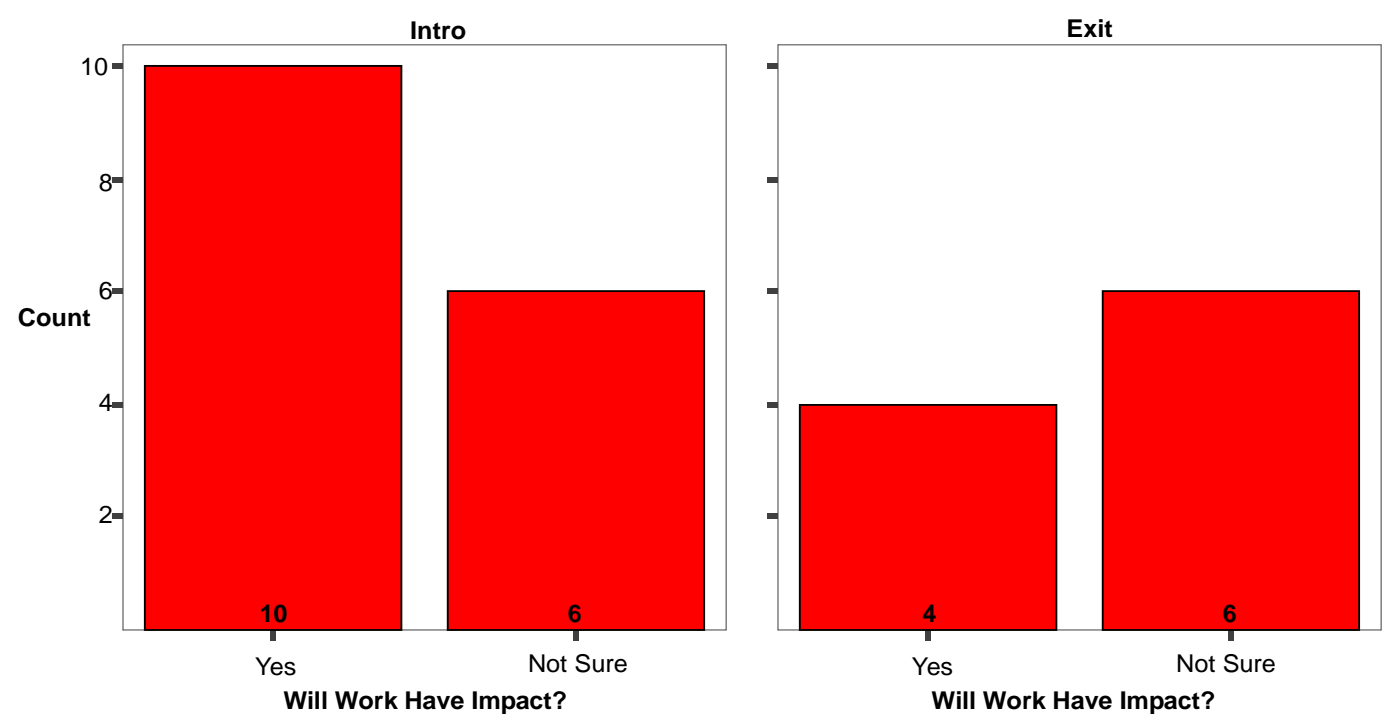

Figure 4. Do you feel your work on this project will have an impact.

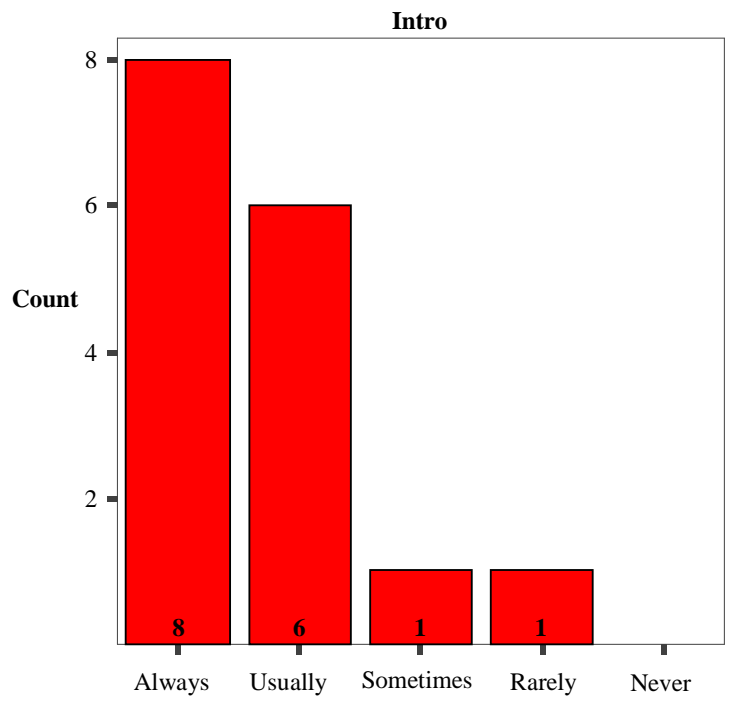

Ability to Identify Giant Hogweed

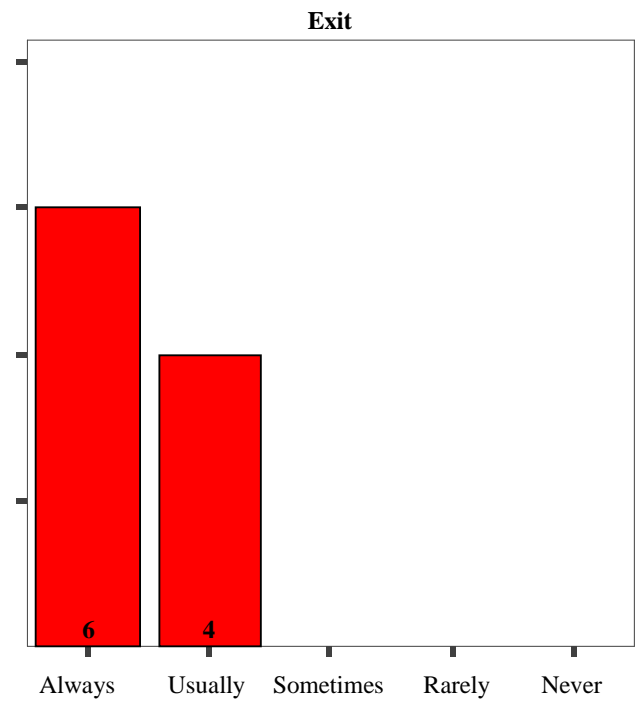

Ability to Identify Giant Hogweed

Figure 5. How easily can you identify Giant Hogweed?

Table 3. Ranks.

\begin{tabular}{lccc}
\hline & Intro/exit & $\mathrm{N}$ & Mean rank \\
\hline Do you feel your work on this project will have an impact? & Intro & 16 & 12.38 \\
& Exit & 10 & 15.30 \\
& Total & 26 & \\
\hline
\end{tabular}

Table 4. Test statistics.

\section{Project impact}

$$
\text { Mann-Whitney U }
$$$$
\text { 2-tailed p-value }
$$

62.000

0.363 
Table 5. Ranks.

\begin{tabular}{lccc}
\hline & Intro/exit & $\mathrm{N}$ & Mean rank \\
\hline Hogweed identification & Intro & 16 & 14.25 \\
& Exit & 10 & 12.30 \\
& Total & 26 & \\
\hline
\end{tabular}

\section{Table 6. Test statistics.}

\begin{tabular}{cc}
\multicolumn{1}{c}{ Hogweed identification } \\
\hline Mann-Whitney U & 68.000 \\
2-tailed p-value & 0.551 \\
\hline
\end{tabular}

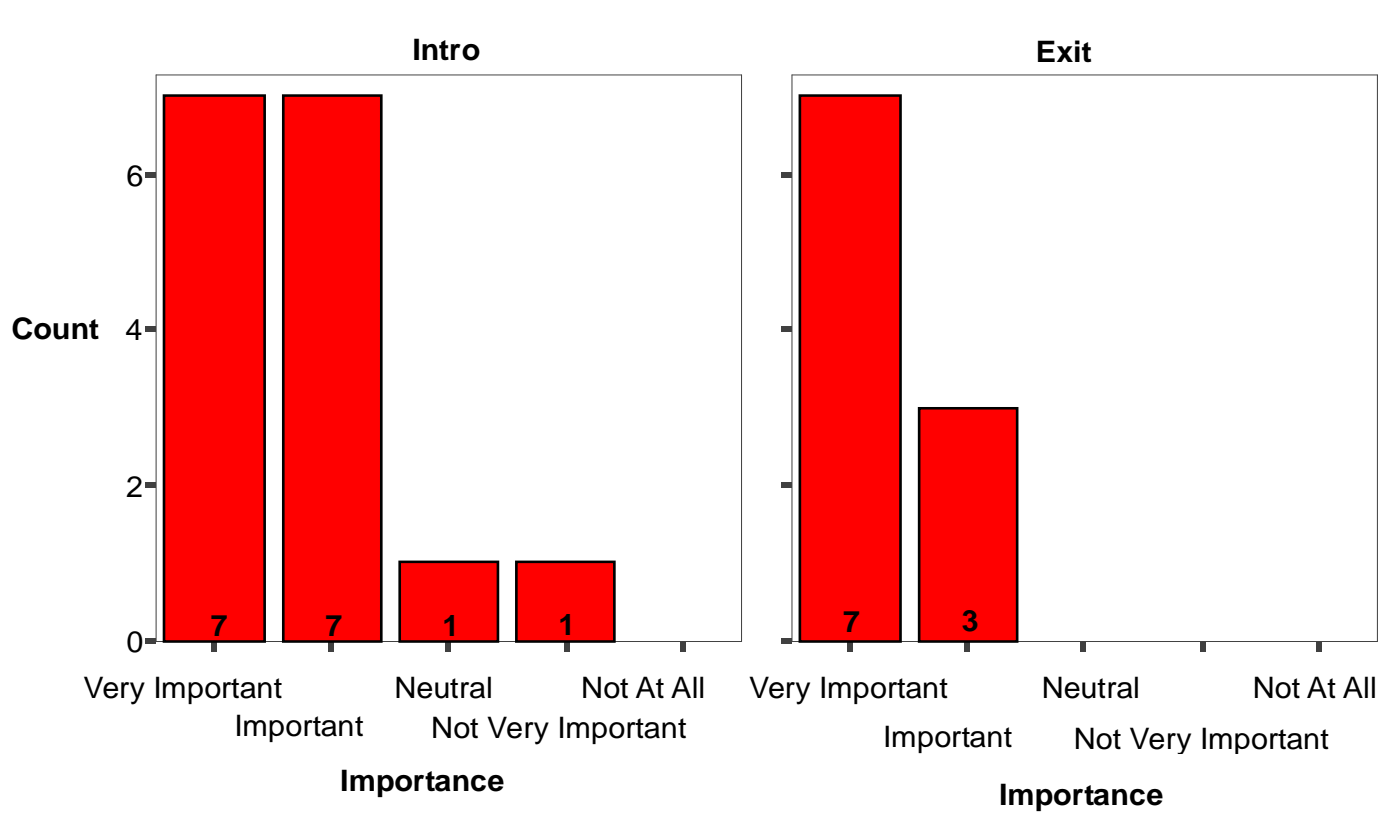

Figure 6. How important are environmental issues to you.

Mean rank of participant response to this question increased (shifted towards a feeling of greater importance of environmental issues) from 15.00 prior to participation to 11.10 after participation-a difference of 3.90 (Table 7). Running a Mann-Whitney test for significance in difference of mean rank between two groups, the p-value of 0.220 (Table 8) indicates a lack of significance, so the null hypothesis should be accepted.

Results (Figure 7) indicate that before participation in this program, $56.25 \%$ of respondents felt it was very important to eliminate Giant Hogweed in Latvia, while 31.25\% felt it was important, and $12.5 \%$ felt neutrally about the issue. There were no responses for "not very important", and "not at all". After participation, 70\% of respondents felt that it was very important to eliminate Giant Hogweed from Latvia, and 30\% felt it was important. There were no responses for "neutral", "not very important", or "not at all". These results indicate that there was a moderate shift to the positive (the issue became more important) in response after participation in the program. As hypothesized, respondents felt that it was more important that Giant Hogweed be eliminated from the Latvian landscape after having participated in the program.

Mean rank of participant response to this question increased (shifted toward participants feeling that it is more important that Giant Hogweed be eliminated) from 14.38 prior to participation to 12.10 after participation-a difference of 2.28 (Table 9). Running a Mann-Whitney test for significance in difference of mean rank between two groups, the p-value of 0.484 (Table 10) indicates a lack of significance, so the null hypothesis should be accepted. 
Table 7. Ranks.

\begin{tabular}{lccc}
\hline & Intro/exit & $\mathrm{N}$ & Mean rank \\
\hline How important are environmental issues to you? & Intro & 16 & 15.00 \\
& Exit & 10 & 11.10 \\
& Total & 26 & \\
\hline
\end{tabular}

Table 8. Test statistics.

\begin{tabular}{cc}
\hline How important are environmental issues to you? & 56.000 \\
Mann-Whitney U & 0.220 \\
2-tailed p-value & \\
\hline
\end{tabular}

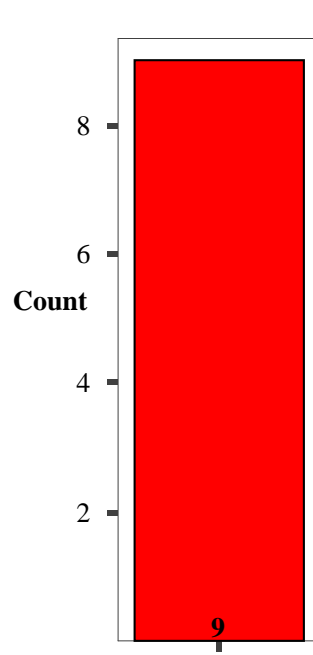

Very Important
Intro

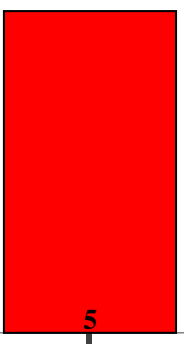

Important

Importance

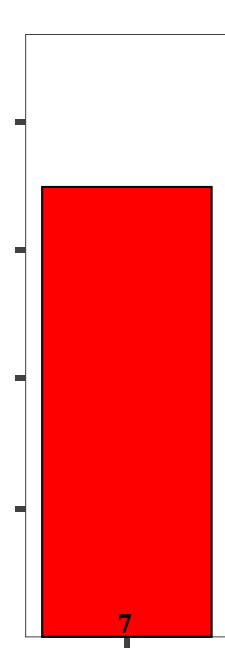

Very Important
Exit

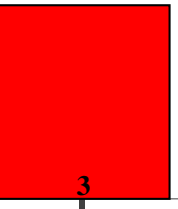

Important

Importance

Figure 7. How important to you is it that giant hogweed be eliminated from latvia.

Table 9. Ranks.

\begin{tabular}{|c|c|c|c|}
\hline & Intro/exit & $\mathrm{N}$ & Mean rank \\
\hline \multirow[t]{3}{*}{ How important is it to you that Giant Hogweed be eliminated from Latvia? } & Intro & 16 & 14.38 \\
\hline & Exit & 10 & 12.10 \\
\hline & Total & 26 & \\
\hline
\end{tabular}

Table 10. Test statistics.

How important is it to you that Giant Hogweed be eliminated from Latvia?
Mann-Whitney U
66.000
2-tailed p-value
0.484

In the following analysis, 2 correlations were conducted to understand the change in relationship (from before to after participation in the program) between the variables:

Results (Figure 8) indicate that prior to participation in this program, 43.75\% of respondents felt the issue of invasive species was very important, while $37.5 \%$ felt is was important, and $18.75 \%$ felt neutrally about the issue. There were no responses for "not very important" or "not at all”. After participation, 80\% of respondents 
felt the issue of invasive species was very important, while $20 \%$ felt it was important. This result marks a dramatic shift to the positive (the issue became more important) in the perception of the importance of the issue of invasive species in respondents. As hypothesized, participation in the PPGIS program has increased the importance of environmental issues in respondents.

Mean rank of participant response to this question increased (shifted toward feeling invasive species is a more important issue) from 15.5 prior to participation to 10.3 after participation—a difference of 5.2 (Table 11). Running a Mann-Whitney test for significance in difference of mean rank between two groups, the p-value of 0.097 (Table 12) is close to significant at the 0.05 level.

\section{Conclusions}

The beta test conducted at Vidzeme University in Valmiera, Latvia during August of 2010 supports the effectiveness of using the web-based PPGIS framework developed in this research for the purpose of inventorying and monitoring Giant Hogweed in Latvia (Research Question 1). The website functions as a tool capable of communicating the goals and purpose of this research, and the role of participants within it. It also provides educational materials to those participants, and is an effective means of collecting and storing point data to be used in GIS/remote sensing analyses to monitor and model the spread of the weed. No obstacles in the flow of participation due to problems in the structure of the program were encountered or reported during or after the test period.
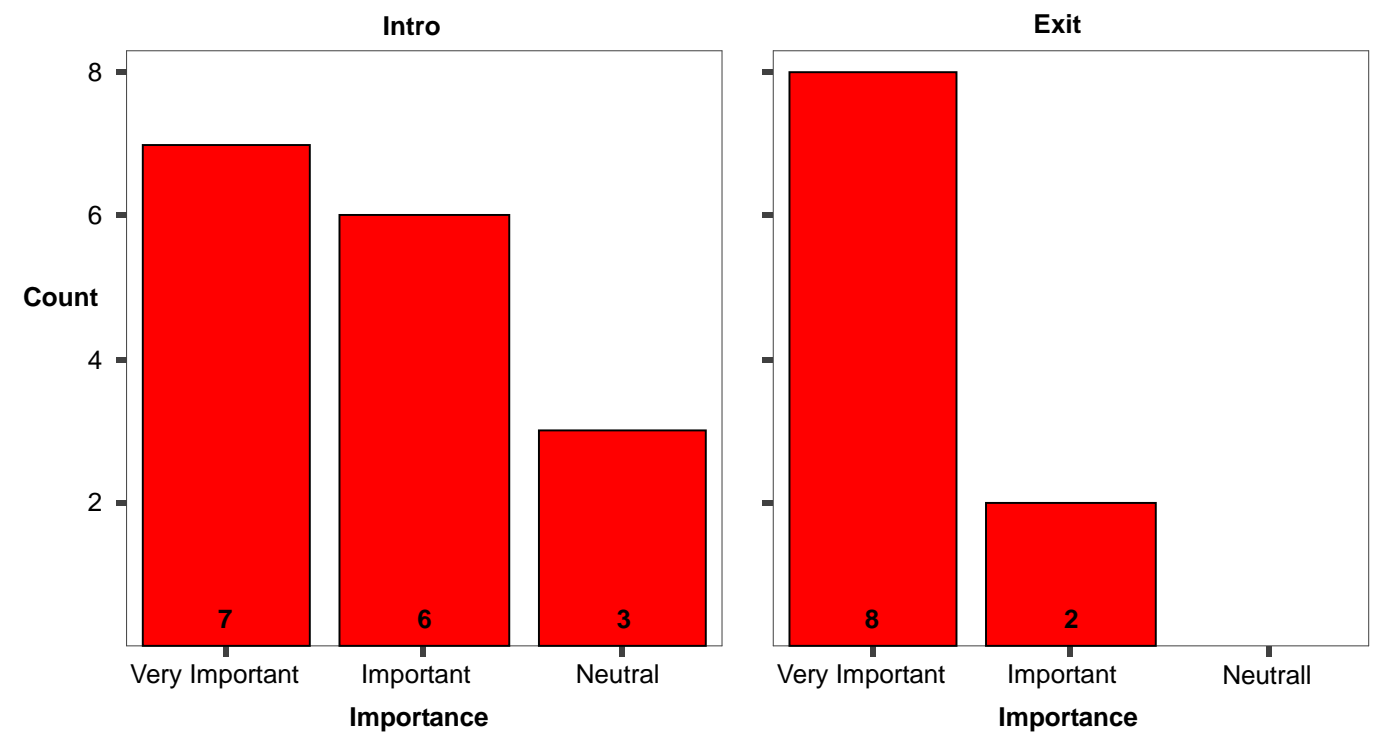

Figure 8. How important to you is the issue of invasive species.

Table 11. Ranks.
\begin{tabular}{lccc}
\hline & & & \\
\hline How important is the issue of invasive species to you? & Intro & 16 & Mean rank \\
\hline & Exit & 10 & 10.50 \\
& Total & 26 \\
\hline
\end{tabular}

\section{Table 12. Test statistics.}

How important is the issue of invasive species to you?

$\begin{array}{cc}\text { Mann-Whitney U } & 48.000 \\ \text { 2-tailed p-value } & 0.097\end{array}$


Statistical analysis performed on participant responses indicate that the educational component of the program has been impactful in providing participants with information regarding the environmental problems that affect their country, and has sensitized them to critical issues (Research Questions 1, 3). Increases in mean rank of participant responses to questions assessing environmental awareness were seen in six survey questions, ranging in value from 0.41 to 5.2, on the 5-point ordinal scale discussed in the Results section above. The greatest increase was found in the variable "How important is the issue if invasive species to you?". This is an encouraging result, as it indicates that the seriousness of the issue is being appropriately stressed in the academic portion of the program, and that participants are receiving the message. In only one question did mean rank decrease (-2.92), "Do you feel your work on this project will have an impact?” as seen in Table 4. These findings suggest that although environmental awareness appears to have increased in participants, more can be done during the educational component to help participants understand more clearly how valuable their contributions are to the project.

Excluding the difficulty in finding an effective means of increasing participation in the PPGIS program, relatively few problems have been experienced in the process of implementing this program. The small sample size of the data (survey responses) collected due to low participation rates in this summer program resulted in the technical invalidation of statistical analysis results. However, further work can use increased sample size to test significance of these analyses. The distance from the site has made logistical issues more difficult, but not impossible. The "out of sight, out of mind" effect may have contributed to the lack of participation following the beta test. Language issues have hampered communication between the research team and Latvian high school teachers, but the true value of this effect is difficult to calculate.

\section{References}

[1] Nielsen, C., Ravn, H.P., Nentwig, W. and Wade, M. (2005) The Giant Hogweed Best Practice Manual: Guidelines for the Management and Control of an Invasive Weed in Europe. Forest \& Landscape, Denmark.

[2] Olson, D.M. and Dinerstein, E. (1998) The Global 200: A Representation Approach to Conserving the Earth’s Most Biologically Valuable Ecoregions. Conservation Biology, 12, 502-515. http://dx.doi.org/10.1046/j.1523-1739.1998.012003502.x

[3] Gavrilova, G.. and Roze, I. (2005) Species of Genus Heracleum L. and Their Distribution in Latvia. 3rd International conference "Research and Conservation of Biological Diversity in Baltic Region", Book of Abstract. Daugavpils University, Daugavpils, 20-22 April, 56.

[4] Gavrilova, G̦. (2003) Report on Investigation of Heracleumin Latviain 2003. Institute of Biology.

[5] Luchette, J.L. and Crawford, T.W. (2008) A Public Participation GIS Application for Citizen Based Watershed Monitoring in the Pamlico-Tar River Basin, North Carolina. Southeastern Geographer, 48, 184-200. http://dx.doi.org/10.1353/sgo.0.0022

[6] Anderson, C., Beazley, K. and Boxall, J. (2009) Lessons for PPGIS from the Application of a Decision Support Tool in the Nova Scotia, Canada. Journal of Environmental Management, 90, 2081-2089. http://dx.doi.org/10.1016/j.jenvman.2007.08.031

[7] Kadoya, T., Ishii, H., Kikuchi, R., Suda, S. and Washitani, I. (2009) Using Monitoring Data Gathered by Volunteers to Predict the Potential Distribution of the Invasive Alien Bumblebee Bombusterrestris. Biological Conservation, 142, 1011-1017. http://dx.doi.org/10.1016/j.biocon.2009.01.012

[8] Eberhards, G. (1984) Reljefs (The relief). In: Latvijasenciklopedija (Encyclopedia of Latvia), 5, Part 2, GER, Riga, 34-41.

[9] Normunds, P. (1993) Black Alder Swamps on Forested Peatlands in Latvia. Folia Geobotanica \& Phytotaxonomica, 28, 261-277.

[10] Bunkse, E.V. (2000) Reality of Rural Landscape Symbolism in the Formation of a Post-Soviet, Postmodern Latvian Identity. Norsk Geografisk Tidsskrift, 53, 121-138.

[11] Kabuce, N. (2007) NOBANIS Invasive Alien Species Fact Sheet: Heracleum sosnowskyi, North European and Baltic Network on Invasive Alien Species. http://www.nobanis.org/files/factsheets/Heracleum_mantegazzianum.pdf

[12] Obolevica, D.(2008) Hogweed and Its Distribution in Latvia. Latvia University of Agriculture.

[13] Heskin, A.D. (1991) The Struggle for Community. Westview Press, Boulder.

[14] Gouveia, C., Fonseca, A., Camara, A. and Ferreria, F. (2003) Promoting the Use of Environmental Data Collected by Concerned Citizens through Information and Communication Technologies. Journal of Environmental Management, 71, 135-154. http://dx.doi.org/10.1016/j.jenvman.2004.01.009 
[15] Wang, X., Yu, Z., Cinderby, S. and Forrester, J. (2007) Enhancing Participation: Experiences of Participatory GIS in Shanxi, China. Applied Geography, 28, 96-109. http://dx.doi.org/10.1016/j.apgeog.2007.07.007

[16] Savage, C. (2006) Google Maps Deconstructed.

http://cfis.savagexi.com/articles/2006/05/03/google-maps-deconstructed 